[T] he most reckless and treacherous of all theorists is he who professes to let facts and figures to speak for themselves, who keeps in the background the part he played, perhaps unconsciously, in selecting and grouping them, and in suggesting the argument post hoc ergo propter hoc"-Alfred Marshall, quoted as epigraph to A Monetary History of the United States 1867-1960, Milton Friedman and Anna Schwarz Jacobson.

\title{
Philosophy and a Scientific Future of the History of Economics
}

\section{Summary and Introduction}

In this essay, I argue that economists have reasons internal to the way that evidence works in the sciences to re-discover the importance of the history of their own discipline. For it is a constitutive element of science - here conceived as an ongoing research practice (as opposed to as an explanatory activity) - that evidence is never discarded forever and is thus historical in nature. Moreover, while drawing on the history of economics and the history of physics, I argue that the history of a discipline can be a source of important evidence in ongoing inquiry. Along the way, I attack a too rigorous distinction between the history of economics and economic history. I distinguish my approach from two closely related positions that emphasize learning from the past for scientific purposes. In my conclusion, I argue that that if economics departments continue to discard the history of economics (and economic history), one of its natural homes is in (history of) philosophy departments, where it can be nurtured among many other theoretical enterprises potentially relevant to the sciences.

II On the Role of History in Scientific Research

Since Thomas Kuhn's Structure there has been an explosion of interest in the history of science. Yet, this has not resulted in a better understanding of the significant evidential role of the history of science in ongoing scientific research. This lack of 
understanding is not surprising because science textbooks and graduate training in the sciences continue to prefer to emphasize either the timeless nature of scientific truth or some natural path toward current science. Moreover, philosophic interest in the rationality of science has tended to emphasize the so-called context of justification and, thus, rational reconstruction and with it a focus on explanation. In contrast, much recent history of science has shown more interest in cultural history, a strain especially important to historians of economics who have wished to introduce departmental and methodological affiliation with science studies and history of science programs (see, especially, Schabas 1993 and 2002). ${ }^{1}$ While these have produced many fine studies of the context(s) and even practice(s) of, say, measurement, standardization, modeling, and precision within the sciences, they have not been especially interested in the substance of evidential arguments within the practice of science as an ongoing research process—one in which theory is (to speak with Marshall) a 'research engine.' Here I call attention to a neglected way in which the history of a discipline matters to the practice of science, especially understood as it pertains to ongoing, empirical enquiry.

Of course, Kuhn is correct to note that "systematic reconstruction" of the past is pervasive in the sciences and science textbooks and that they often "badly misrepresents the past." It appears that even Kuhn's phenomenal and enduring success has had little influence on the practice of textbook writers and (under-) graduate education within the sciences. But it does not follow that "the sciences cut themselves off from their past."

\footnotetext{
${ }^{1}$ Margaret Schabas (1992) "Breaking Away: History of Economics as History of Science, HOPE 24: 187203, and also Margaret Schabas (2002) "Coming Together: History of Economics as History of Science" in The Future of the History of Economics, Annual Supplement to Volume 34 History of Political Economy, edited by E. Roy Weintraub (Durham: Duke University Press), 208-225.
} 
(Kuhn, quoted in Weintraub 2002: 2) ${ }^{2}$ I do not mean just to make the logical point that badly misrepresenting the past is not the same as cutting oneself off from it. I dispute Roy Weintraub's claim that "in neither mathematics nor physics does history have a place." (Weintraub 2002: 2) Leaving aside the special case of mathematics, the (real!) past does play a very important, principled role in science, but it is obscured even if (and especially because) history is not part of the teaching curriculum (in context the concern of Weintraub).

In particular, history enters in the current research practice of science in at least two ways: first as a source of "the data." Here "the data" is not so much understood as the "tribunal" in front of which theory is held accountable or which it is "tested" against; it is seen rather as a source of the generation of theories and their continuous, ongoing development. Second, as my sometime collaborator, George Smith, argues, "when theory is embedded in ongoing research, the history of the development of the research can itself be a telling form of evidence, especially on questions about what the research has really accomplished." ( "Testing Newton, Then and Now," paper delivered at University of Pittsburgh, 11/11, 2005) This second perspective is crucial if one wishes to evaluate the success or failure of theories over time. Given the nature of the present occasion, I focus exclusively on the first.

Instead of offering many examples from the practice of science, I take advantage of a coincidence. While preparing a draft of this paper, I received the following description of a doctoral program through a listserv I subscribe to: "The Historical Astronomy group [at the University of Durham] conducts research into two

\footnotetext{
${ }^{2}$ E. Roy Weintraub “Will Economics Ever have a Past Again?” Introduction to Weintraub 2002: 1-14. Of course, Kuhn did not deny that a distorted/Whiggish history serves various pedagogical functions in science-training and can create a sense of 'maturity' about the science.
} 
overlapping areas: (i) the history of early astronomy, in particular the development of astronomy in ancient Mesopotamia, Greece and China; and (ii) the use of historical astronomical data in problems of modern science." ${ }^{3}$ I was (pleasantly) surprised that there is a group that explicitly conducts research in both areas. (I was even more pleased to learn that this group has a home in a department of physics. $)^{4}$

It is, of course, no surprise that in astronomy we find some concern with history. Important data in astronomy spans several civilizations: from "ancient Mesopotamia, Greece and China," mentioned in the advertisement, to the medieval Arabs and efforts in modern "science." As Noel Swerdlow taught me, "from Copernicus on people use ancient observations for deriving parameters of mean motions, which require observations as far apart as possible," (personal communication, March 25, 2006). Without this extensive data many important cyclical "phenomena" would be unknown (e.g., the precession of the equinoxes; the orbits of comets; the great inequality in the motions of Jupiter or Saturn; sunspot-cycles, etc), and the Newtonian synthesis of astronomy and physics would have been impossible to achieve (or, perhaps, contemplate). Many of the "phenomena" that Newton's theory set out to account for, and many of the striking predictions - which led people to accept Newton's theory, at least as a useful research tool, despite potential metaphysical and methodological qualms about the plausibility of action at a distance - involve appeals to such long running data. (One

\footnotetext{
${ }^{3}$ On HOPOS listserv, 26 January 2006. A copy of the advertisement can be found at: http://luddite.cst.usyd.edu.au/archives/galileo/2006/000055.html, accessed on 25 March 2006. The research group's web-page is: http://www.dur.ac.uk/physics/research/groups/?mode=centre\&id=199, accessed on 25 March 2006.

${ }^{4}$ After some further research I learned that the American Astronomical Society has a Historical Astronomy division and that the International Astronomical Association has a subdivision (Commission 41) devoted to the history of astronomy. (The latter, however, seems to be exclusively devoted to the history of astronomy rather than "the use of historical astronomical data in problems of modern science.") Of course, there are very few job-openings for historians of astronomy in astronomy/astrophysics departments.
} 
could do worse than to consult Adam Smith's "The History of Astronomy” on this matter. $)^{5}$ The history of astronomy is essential to the discovery of universal gravitation. If one removes the astronomical context to Newton's theory, one is left with a science of mechanics that would have no reason to suspect the existence of or investigate universal gravity as a fundamental force of nature. (I am not suggesting that astronomy or its long running data made this discovery inevitable.)

Some part of science will have a historical component in so far a) it aims to make claims about the behavior of models, systems, and institutions (etc) over time and b) it has a norm that encourages inspection and checking or revision of "the data." For even if some sciences do not require time-series data (because they are not trying to explain changes over time), the evidence that supports a theory becomes historical in nature as time passes.

At this juncture one may be tempted to make a distinction (well known in economics) between the history of astronomy or economics and astronomical or economic history. It may appear that I have not shown that the history of the discipline or other antecedent relevant practices matter, but only that for some pertinent parts of science history can be relevant to inquiry. However, in order to preserve and help (re-) interpret the historical "data," a set of skills and practices are required that are often not emphasized in the training of scientists (so much so that Kuhn and Weintraub come to their conclusions that history appears to have no place in science). This is why in my example I focus on data derived from entirely different civilizations. In the sixteenth and

\footnotetext{
${ }^{5}$ It is well known that Smith offers a psychological account of the origin of scientific activity with particular emphasis on aesthetic considerations. However, for Smith's adoption of Newtonian realism see Eric Schliesser "Realism in the Face of Scientific Revolutions: Adam Smith on Newton's Proof of Copernicanism," (2005) British Journal for the History of Philosophy, 13(4): 697-732. In particular, I call attention to Smith's endorsement of Newtonian predictions and physical explanations.
} 
seventeenth centuries, an element of ongoing science was to recover and assimilate data from past practices; this required major linguistic effort as well as attempts to translate the data from different paradigmatic practices. (I am understating the situation: through the $17^{\text {th }}$ century "history of astronomy is living astronomy and to be taken seriously." The results of these labors are achievements that can continue to be refined and questioned. So in order to be able to recover the historical record for present evidential purposes, the academic division of labor must encourage the existence of some specialized historians with their own intellectual infrastructure.

Thus, I deny that there is always a firm distinction between economic history and the history of economics. Adam Smith's long "Digression on Silver" at the end of Book I of Wealth of Nations (WN) is as much an exercise in economic history as it is history of economics. The same is true of Milton Friedman's and Schwarz Jacobsen's Monetary History of the United States, which admits in its preface that the “[accompanying] analytical narrative... significantly affected [the] statistical analysis." (xxi) Economic history (whether it contributes to ongoing research in economic theory or not) will always require considerable knowledge of the history of economics because the data of the former are often embedded in the practices and doctrines of the past. Moreover, as Adam Smith recognizes in the "Introduction" to Wealth of Nations, the economic policies of "princes," and economic activity more generally, are often

\footnotetext{
${ }^{6}$ Noel Swerdlow, personal communication, March 26, 2006. The remainder of Swerdlow's position is worth quoting: "Through, say, the middle of the seventeenth century, not only were ancient observations of use, but ancient astronomy, meaning mostly Ptolemy's Almagest was still of use, that is, it wasn't just history, it was astronomy worth reporting along with, say, Copernicus or Tycho or Kepler, as it was still taken seriously, still very much alive. It didn't really matter if one was heliocentric or geocentric, Ptolemaic, Tychonic, or Copernican, the models for the motions of the sun, moon, and planets in the Almagest still had something to teach, and even more so did Ptolemy's methods of deriving parameters from observations. The work that shows this the most is Gambattista Riccioli's Almagestum novum (1651)..."
} 
influenced by theories of political economy past and present. Finally and not insignificantly, rational expectations may differ if theory differs.

This reliance on history can go very deep. For example, the announcement of the famous 43 arc-second per century anomaly in the procession of Mercury's perihelion (in the middle of the nineteenth century) was itself based on observation of Mercury's transits across the Sun dating back to 1631. It is useful for the argument I am developing that the 43 second anomaly was itself a revision, based on a new look at the data and theory, of an earlier estimate of 38 seconds. This anomaly is not something that can itself be 'observed' in the data. It is not curve-fitting. It presupposes commitment to Newtonian theory and the evidence supporting it and enabling revisions to it accumulated over two centuries. (George E. Smith, 2005.) It is often not appreciated that the 'observation' that led to the demise of Newtonian theory was made possible by its historical development and its history of success. (The anomaly would not have been 'observable' when Newton first formulated his theory.) As I indicate above, Newtonian theory had by this time itself relied on historical data in its development and subsequent entrenchment over time as the most promising theoretical research program. This example is significant in a further way; it shows that one cannot always insulate the a-historical part of science (mechanics) from the more historical part (orbital astronomy).

Furthermore, a widely shared epistemic principle is that it is always available to a scientist to re-open discussion of an established theorem, principle, or "fact." A crucial and not un-common way to do this is to re-analyze "the data" or the theories that allowed one to distinguish data from noise. (Sometimes re-analysis of data makes a supposed problem or objection disappear.) When an issue is of great importance to theory as 
ongoing research, there can be constant return to source-data. Given this commitment, there is a place for historians of a discipline (even or especially if the 'data' was not understood as such or in the same way in different civilizations or epochs). Sometimes the historian's skills are needed to help recover, uncover, (re-)interpret, and contextualize (theoretically or in terms of measurement) the relevant data. This is so because data are not just discovered in the wild, as it were, and available to inspection. Instead they are themselves the product of complex interaction between instruments (and -- as Duhem pointed out long ago -- the theories presupposed in them), ${ }^{7}$ theories (models, assumptions, etc), observers (and their environments), and 'nature. ${ }^{8}$ So my argument follows from a fairly innocent assumption about the nature of scientific enquiry: that data are embedded in theories and measurements. This gives rise to a certain form of practical or psychological incommensurability between knowledge presupposed in current research practice and past data gathering strategies and recording. Special historical skills allow the gap to be closed. ${ }^{9}$ My argument does not require commitment to the stronger assumption of so-called theory-ladenness of data. ${ }^{10}$

\footnotetext{
${ }^{7}$ Pierre Duhem (1991; Reprint edition) The Aim and Structure of Physical Theory Translated by Philip P. Wiener Princeton: Princeton University Press, especially chapter 4. My whole argument is, of course, deeply indebted to Duhem's insights.

${ }^{8}$ I discuss more of these issues pertaining to economics in Schliesser "Milton Friedman, Positive Economics, and the Chicago Boys," (in progress). For a very sophisticated treatment, see M.J. Boumans (2005) How Economists Model the World into Numbers London and New York: Routledge.

${ }^{9}$ This is Adam Smith's view (Schliesser 2005), who also nicely described the phenomenology of this kind of psychological incommensurability in his fragment on "The History of the Ancient Logics and Metaphysics" in Essays on Philosophical Subjects (1982) Edited by W.P.D. Wightman and J.C. Bryce, Indianapolis: Liberty Fund, $₫ 10,128$.

${ }^{10}$ In the body of the paper, I focus on sciences that deal with long-range historical phenomena (one can add examples from archeology and climatology). But, as Sabina Leonelli first reminded me, the day is quickly approaching in some of the experimental sciences that rapid technological progress can make (tacit and theoretical) knowledge about instruments/experimental set-up obsolete within a 'generation' of one's $\mathrm{PhD}$ training. Sciences that use sophisticated computer-modeling techniques/calculations may face the same problem in recovering insight in properties of underlying code. So in such sciences historians of the discipline may become increasingly required to ensure continuity of research and theory.
} 
Of course, not all past data relevant to modern inquiry is exclusively or even primarily influenced by past (proto-) economic theory. So, a cultural history of science can be necessary and useful to the evidential practice(s) of ongoing science, in so far as this history is also concerned with the 'science' of the past. To put this in terms familiar from the so-called 'science wars' familiar from science studies in the 1980s and 90s, if historians of economics wish to offer products to be consumed by economists they needs to offer both 'internal' and 'external' history of economics that might be useful to current and future economic enquiry.

My argument implies - pace Weintraub - that historians of economics need not "insist on their autonomy from science." (Weintraub is quoting and endorsing the historian of science, Theodore Porter.) I reject the view that the study of the history of economics ought to retreat "into a home...within departments of history or history of science programs," if that entails that "the standards by which a piece of work in the history of economics must be judged are...specifically, the standards...employed by professional historians to evaluate and appraise historical writing" $" 11$ (emphasis added). This dooms history of economics to irrelevance within economics departments. Thus, I reject the mutual rejectionist position: mainstream economics rejects the relevance of history of economics, and in turn history of economics folk should reject the mainstream and take their work to a department that appreciates them for who they are: historians. To

\footnotetext{
${ }^{11}$ E. Roy Weintraub "What Defines a Legitimate Contribution to the Subdiscipline "History of Economics?" Editorial posted: 1996-09-09. http://www.eh.net/HE/hes list/Editorials/weintraub.php Accessed 25 March 2006. I don't want to overemphasize the differences between Weintraub's position and mine. We both take the relative professional success of economic historians as a model worth emulating by historians of economics. However, on my model economic history is a partial intellectual failure if it does not even aim to contribute to the improvement of the analytic tools, the accuracy of the data of and/or conceptual apparatus useful to (mainstream) economic theorizing. Mark Blaug reminds that some economic historians have worked hard to be relevant. See, besides the well-known work by Fogel, for example, Joel Mokyr The Gifts of Athena: Historical Origins of the Knowledge Economy (Princeton, 2002).
} 
be clear: I do not wish to exclude those that treat history of economics either as an autonomous or critical-of-the-'mainstream' enterprise from history of economics. ${ }^{12} \mathrm{My}$ argument, presupposes that there will be an intellectual division of labor among historians of economics, some of which may find a home in history and science studies. ${ }^{13}$

In order to avoid confusion, the position I defend should be distinguished from two related uses of history in ongoing practice. ${ }^{14}$ First, it is well known that history can be a source of inspiration to develop new hypotheses to improve present practice. Adam Smith's emphasis on sympathy, for example, has been cited in this regard in recent literature on experimental economics, behavioral economics, and neuro-economics. ${ }^{15}$ In late twentieth-century economics, Adam Smith plays a special authoritative role in such 're-discoveries' by people across the intellectual spectrum: Hayek, Buchanan, Sen, Vernon Smith, Coase, etc. (I leave aside how 'historical' their favored version of Adam Smith is.) My view is not incompatible with this practice, but it cannot be reduced to it. Second, Hasok Chang, a historically inquisitive philosopher of science, has advocated what he calls "complementary science," that is, the use of history and philosophy of science to "generate scientific knowledge in places where science itself

\footnotetext{
${ }^{12}$ Moreover, some historians of economics are not so much critical of the mainstream as wish to broaden its discussion, make it more self-aware/reflexive, or shape its future. For very valuable comments on the social, institutional, historical, political, and conceptual origins as well as the implications of the mutual rejectionist position, see Steve Fuller (1996) "Who's Afraid of the History of Contemporary Science?" in The Historiography of Contemporary Science and Technology, edited by T. Soederqvist Reading: Harwood. Monthly Guest Editorial for HES, http://www.eh.net/ HisEcSoc/Resources/Weintraub/Fuller.shtml, accessed March 7. 2006.

${ }^{13}$ It should be noted that there are only few science studies programs (some of which have rather fragile institutional support), and most of these are devoted to supporting research about either the medical/life sciences and/or the physical sciences. It is to be doubted that science studies programs can support the professional careers of historians of economics at more than a fraction of the existing number of historians of economics that at present have employment in economics departments.

${ }^{14}$ I ignore other, potentially more important roles that history can play in shaping the aims and structure of evidential practices in the sciences (cf. Paul Feyerabend (1989) "Realism and the Historicity of Knowledge," The Journal of Philosophy 86:8: 393-406.)

${ }^{15}$ See also the work by Sandra Peart and David Levy (2005) The "Vanity of the Philosopher" (Ann Arbor: The University of Michigan Press) which mixes history and theorizing.
} 
fails to do so." Chang's argument follows from his explicit acceptance of Kuhn's diagnosis that "normal science" can "only function if certain fundamentals and conventions are taken for granted and shielded from criticism." The success of paradigms and their displacement of certain questions sometimes entails the "loss of knowledge, actual and potential." Chang, thus, not merely explains why in response to this state of affairs "heterodox" ${ }^{" 16}$ approaches may find a refuge in the history and philosophy of a particular science, but also advocates their practice as a form of "complementary science" (Chang 2004, 236-7). ${ }^{17}$

Chang's account of a "complementary science" offers an exciting model for those drawn to the history of economics with a critical perspective on the so-called mainstream. It is, however, unclear how the 'results' of such a heterodox complementary science can be accepted as "scientific" by the mainstream. ${ }^{18}$ Chang and I agree that the practice of history (and philosophy) of science can be more than just conforming to a historian's task and standards. It can aim to uncover lost knowledge. But my position also allows for an important role for history within the mainstream, even if it will require better marketing and superior products to make the mainstream receptive to it. ${ }^{19}$ Even if

\footnotetext{
${ }^{16}$ See the essays by Sheila Dow, Peter Boettke, and Antony Brewer in Weintraub 2002.

${ }^{17}$ Hasok Chang (2004) Inventing Temperature: Measurement and Scientific Progress Oxford: Oxford University Press.

${ }^{18}$ In private correspondence (20 April, 2006), Hasok Chang argues that "we need a distinction between neglect and suppression. Specialist science will suppress some things because they conflict with its own premises, and neglect other things simply because they are uninteresting or unimportant. In the latter category, complementary science may produce results that orthodox science can happily allow to stand. This is slightly similar to the difference between "alternative" medicine and "complementary" medicine, though the meanings of those terms are not always clearly distinguished. An orthodox Western doctor may freely grant that all sorts of traditional or exotic herbal remedies can work, and may even grant that acupuncture relieves pain, but will not accept the homeopathic claims about the "memory of water", etc. I think complementary science should embrace both the neglected and the suppressed."

${ }^{19}$ My position is not far removed from the spirit of a "scientific philosophy" proposed by Michael Friedman (2001) in Dynamics of Reason, Stanford . Friedman emphasizes the positive role that philosophy has played and can continue to play in formulating novel principles for ongoing and future science(s) and
} 
economics is a so-called mature, normal science (in this essay I bracket what it would it would take to be a 'normal' science in Kuhnian sense $)^{20}$ then in the context of regular ongoing inquiry there is an untapped demand for history of economics that is neither Whiggish, anachronistic, nor heterodox. If it is still immature, then my vision for the history of economics can help change that. Of course, like in all entrepreneurial activity, it is not clear that there will be a market for the kind of product I advocate; economic theoreticians and econometricians may feel they can go on just fine without the kind of comparative, historical data that I am promoting. Knowledge of economic history and history of economics may never again be thought relevant for ongoing inquiry, or be fairly marginal in it (e.g., the status of history of astronomy in astrophysics).

\section{Conclusion and Disciplinary Consequences}

The current decline of interest in the history of economics among economics departments suggests (among other things) that historians of economics are not offering the right kind of product to economics as an ongoing form of inquiry. Though I offer a diagnosis of the future potential of the history of economics that competes with that offered by Weintraub, Schabas, et al, I agree that the history of economics may need to find at least a partial and temporary home in other departments. I emphasize the partial nature of such a situation because my vision requires that at least some historians of economics continue to be trained to understand the cutting-edge tools and questions of mainstream inquiry. I emphasize the temporary nature because history of economics

\footnotetext{
helping in consolidating and interpreting new paradigms. Not unlike Friedman, I also offer this as a positive vision for philosophy.

${ }^{20}$ It is not so long ago that Marshall called for a positive science of 'economics.' (I thank Leon Montes for discussion of this point.)
} 
should aim, in part, at (a return to) relevance to ongoing science. History departments are unlikely to be welcoming to this stance. In my view, philosophy departments and history and philosophy of science departments are more promising avenues.

Moreover, many philosophers instinctively agree that even if we assume, for the sake of argument, that economic theories can be genuinely scientific (objective, true, falsifiable, reliable, etc), they cannot escape being philosophic in the sense of being enmeshed in values and, thus always open to philosophic reconsideration. So one of the natural homes of the history of economics is in (history of) philosophy, where as the study of (the history of) political economy it can be nurtured among many other theoretical enterprises potentially relevant to economics (and other sciences), in particular, Bayesian decision theory, game theory, and normative (utilitarian) ethics. Various social factors incline philosophers to accept work on formal theories as philosophical (and not as a sign of lack of professional competence). My proposal also takes advantage of philosophers' desire to accommodate social and institutional demands for 'contemporary relevance,' and their wish to interpret this differently than the recent vogue for applied ethics (which has dubious intellectual status in the philosophy profession). This helps explain interest in establishing so-called PPE (i.e., Philosophy, Politics, Economics) programs. ${ }^{21}$ I call on historians of economics to explore this option. So my approach offers a promising professional path for those who wish to combine theoretical interest in economics with historical and philosophic sensitivity. If they have heterodox inclinations Hasok Chang offers them a promising vision; if they have more constructive intuitions they should follow my advice. In competition and

\footnotetext{
${ }^{21}$ As the mention of PPE programs also suggests, many of my arguments about philosophy carry over into political science as a potential home for history of political economy.
} 
collaboration with those inspired by Schabas and Weintraub, these three approaches can find spaces in economics departments, history and history of philosophy of science programs, political science departments, business schools, and philosophy departments (etc). (One should not fear the inevitable competition over scarce resources.) They will do so by building on existing intellectual infrastructures. Thus, I offer a vision that can appeal to the self-interest and high ambition of those that wish to make the future of the economics and its history. ${ }^{22}$

Eric Schliesser, Department of Philosophy, Syracuse University, 541 Hall of Languages, Syracuse, NY 13244-1170; nescio2@yahoo.com Research Fellow (2006-9), Netherlands Organisation for Scientific Research, Philosophy Department, Leiden University. Research Associate, Amsterdam Research Group in History and Methodology of Economics, Faculteit der Economische Wetenschappen en Econometrie, Universiteit van Amsterdam

\footnotetext{
${ }^{22}$ I thank Erik Angner, Hasok Chang, Jerry Evensky, David Levy, Leon Montes, Ivan Moscati, Robin Neill, Warren Samuels, Margaret Schabas, Abe Stone, Noel Swerdlow, Paola Tubaro, audiences at DEMUS at the Free University of Amsterdam and ESHET, Porto (2006), and, especially, Sarah Brouillette for helpful comments. The usual caveats apply.
} 